Entrevista 


\section{Água enquanto disputa epistêmica e política para além dos três estados Mejía Ayala \\ da água

\author{
Entrevista com o professor Carlos Walter Porto-Gonçalves ${ }^{1}$
} \\ Aos Companheiros e Companheiras de Ríos Vivos, Colômbia \\ Aos Companheiros e Companheiras de MODATIMA, Chile \\ Aos Povos das Águas dos rios Isiboro e Secure - TIPNIS, Bolívia \\ Aos Camponeses e Camponesas de Correntina, Bahia-Brasil}

Geógrafo brasileiro, formado pela Universidade Federal do Rio de Janeiro e professor titular do Departamento de Geografia da Universidade Federal Fluminense, o Dr. Carlos Walter Porto-Gonçalves ${ }^{2}$ foi presidente da Associação de Geógrafos Brasileiros entre 1998 e 2000 e é coordenador do Laboratório de Estudos de Movimentos Sociais e Territoriais (LEMTO), bem como membro do grupo de trabalho "Hegemonías y emancipaciones" do Consejo Latinoamericano de Ciencias Sociales (CLACSO). Ele foi galardonado em 2004 com o Prêmio Chico Mendes em Ciência e Tecnologia pelo Ministério do Meio Ambiente do Brasil; em 2008, com o prêmio Casa de Las Américas, concedido em Cuba; e, em 2019, com o Prêmio Milton Santos otorgado durante o Encontro de Geógrafos da América Latina (EGAL), realizado na cidade de Quito, Equador. Seu pensamento contribuiu profundamente para a discussão sobre ecologia política, movimentos sociais e questões ambientais em geral, tornando-o um dos geógrafos, pesquisadores e autores mais influentes da área latino-americana. É autor de várias publicações sobre geografia humana e social, que incluem principalmente os livros: "A Globalização da Natureza e a Natureza da Globalização" (Civilização Brasileira, 2006) e "Amazônia: encruzilhada civilizatória. Tensões territoriais em curso" (CIDES-UMSA, 2018).

1 Entrevista realizada por Wladimir Mejía Ayala (WMA), doutor em Geografia, professor da Universidad Pedagógica y Tecnológica de Colombia (Pós-Graduação em Geografia EPG / UPTC-IGAC), em Bogotá. Editor da revista Perspectiva Geográfica.

2 A revista Perspectiva Geográfica agradece ao professor Carlos Walter Porto-Gonçalves (CWPG) por compartilhar seus conhecimentos de forma ampla e desinteressada. Este projeto teve início em 2019 na cidade de Bogotá e terminou em 2020. A entrevista foi dividida em três momentos / fragmentos / reflexões principais, cada um dos quais o professor Carlos Walter deu os Títulos: 1. Um lugar epistêmico (e político) privilegiado; 2. O discurso da escassez; e 3. Para além da Colonialidade 


\section{Um lugar epistémico (e político) privilegiado ${ }^{3}$}

WMA: Professor Carlos Walter, você tem sido um intelectual essencial para a América Latina na evolução do pensamento ecológico-político; por mais de 20 anos, conseguiu articular a geografia em favor das lutas sociais dos grupos sociais em situação de subalternização. Em que momento e circunstâncias a questão/conflito da água começa a fazer parte dos seus interesses como pesquisador?

CWPG: O tema/a questão da água entrou em meu horizonte de preocupação e investigação propriamente científica não a partir de um a priori, isto é, de uma decisão de investigar a água. Cheguei a me surpreender quando a partir de determinado momento, passei a receber convites para falar sobre a água. Afinal, jamais me dedicara a investigar esse tema especificamente. No entanto, os que me convidavam me indicavam artigos em que eu tratava do tema como, por exemplo, um artigo que escrevi nos anos 1990 cujo título é "As Minas e os Gerais ${ }^{4}$ : breve ensaio sobre desenvolvimento e sustentabilidade a partir da Geografia do Norte de Minas"5. Na verdade, tratava-se de um artigo em que analiso as lutas camponesas nesta região do Brasil, onde a questão da água é parte do conflito social. Eis de onde a água adentrou meu horizonte de preocupações: o conflito social ${ }^{6}$.

WMA: Ecomo podemosentender oconflito pela água como um lugar privilegiado epistêmico e político, tal como você propõe, que amplia a compreensão da questão para além da água em seus três estados - sólido, líquido e gasoso?

3 Ao longo desta entrevista, o professor refere, expandindo, grande parte das informações contidas nos artigos já publicados

4 O título "As Minas e os Gerais" é um recurso linguístico-poético em que faço um contraponto ao nome do estado (província ou departamento) de Minas Gerais. Mina, em português, significa também uma fonte de água, onde a água mina. E gerais diz respeito às terras que não têm dono, é terra comum, é terra de todos, é terra geral. Nesse artigo analiso como as minas de água secaram depois que os gerais, terras gerais, foram privatizados pelas grandes empresas com monoculturas de eucalipto. Assim, as minas já não minam posto que os gerais foram privatizados, como finalizo o artigo (Nota de CWPG).

5 Gonçalves, C. W. P. (2000). As Minas e os Gerais - Breve ensaio sobre desenvolvimento e sustentabilidade a partir da Geografia do Norte de Minas. In: Guimarães, P. W. et al. Cerrado e desenvolvimento: tradição e atualidade. Montes Claros: Unimontes, pp. 19-45

6 Já nos anos 2000 escrevi três ensaios em que especifico o tema da água, a saber: "Água não se Nega a Ninguém: a necessidade de ouvir outras vozes" (2007), "A Luta pela Apropriação e Reapropriação Social da Água na América Latina" (2008) e "A Geopolítica da Água e a Crise do Conhecimento" (2011). Em todos esses artigos observe-se que trabalho a partir de conflitos que implicaram lutas sociais em torno das condições metabólicas necessárias para a reprodução da vida: terra-água-fauna-flora (Nota de CWPG). 
CWPG: Tenho insistido que o conflito é um lugar/momento/conceito privilegiado do ponto de vista epistemológico, haja vista que o que está sendo objeto de um conflito apresenta, no mínimo, duas versões, duas leituras possíveis e, com isso, sempre amplia a compreensão da sociedade sobre o que está sendo posto em questão. Afinal, o conflito é a manifestação empírica das contradições de uma determinada sociedade num determinado momento/ lugar, é a contradição em estado prático onde a dialética se manifesta concretamente aberta às vicissitudes históricas geograficamente situadas. A água emergiu assim como condição de/da vida de grupos sociais que se viam privados dela; surgiu como tema político e como tema de justiça social/ ambiental. E, assim, a água emergiu não a partir dos gabinetes de gestores estatais, de organizações internacionais ou das grandes empresas, mas sim a partir dos grupos sociais que colocavam a água como reivindicação, quase sempre para a produção/reprodução da vida. É desse lugar/momento e junto a esses grupos sociais que passei a incorporar a água como questão epistêmicopolítica. Foi a partir daí que me dei conta de que a água não podia ser tratada separada da vida, o que colocava em xeque a divisão do trabalho científico, ondea água está associada às ciências naturais. Não resta dúvida, entretanto, que minha formação como geógrafo teve grande influência nessa leitura, tendo en conta que a formação disciplinar em geografia abarca o estudo da relação sociedadenatureza, ainda que prevaleça uma forte tradição que separa a geografia social da geografia da natureza ${ }^{7}$. Mas a geografia como tal não tratava o conflito social, tema que estava adstrito às ciências sociais. Foi rompendo essas barreiras epistêmicas que o tema/a questão da água se colocou a partir de outras perspectivas, o que implica dizer que se apresentava como questão epistêmica e política ao mesmo tempo. Afinal, no conflito social grupos sociais colocavam a água como condição da vida e aportavam seus conhecimentos -outras epistemes- que não comportavam a separação natureza-sociedade, a separação da água de seus territórios de vida. A ideia do quarto estado da água começava a se infiltrar em outros terrenos, se me permitem a metáfora.

WMA: Embora os grupos sociais tivessem colocado a água como condição de vida e contribuído com seu conhecimento, a nível histórico, suas vozes foram 
silenciadas. É assim que o paradigma científico moderno -masculino, burguês/ gestor, branco, ocidental- pode ser associado ao conflito pela posse e uso da água?

CWPG: Diferentes autores, entre outros Aníbal Quijano, Immanuel Wallerstein, Giovanni Arrighi e José Luiz Fiori, vêm chamando a atenção que estamos vivendo uma profunda crise do padrão de poder/saber do sistema mundo (caos sistêmico). O tema/a questão da água me parece que deva ser entendido como parte desse contexto. Afinal, o padrão de poder que se constituiu desde 1492 e que nos governa até hoje como sistema centro-periférico não só conformou um sistema de poder geopolítico e geoeconômico, mas também conformou uma geopolítica do conhecimento (Walter Mignolo). Essa geopolítica se fez através do epistemicídio, ou seja, desqualificando/inferiorizando outras formas de conhecimento desenvolvidas a partir de outros lugares/outros povos. A pior herança do colonialismo, nos alerta Boaventura de Sousa Santos, é o desperdício dessas outras experiências humanas. Assim se impôs uma determinada forma de conhecimento como se fosse $O$ Conhecimento e um único conhecimento como universal como se não houvesse outros conhecimentos passíveis de serem universalizados (pluriversidade). Esse conhecimento se via a si mesmo como atópico, como se fosse de lugar nenhum, a hybris do ponto zero, de Santiago Castro-Gomez. Na verdade, um conhecimento nascido numa província específica do mundo, a Europa.

Nessa matriz hegemônica de conhecimento a homem é o centro do mundo - antropocentrismo- e está autorizado a exercer a dominação da natureza que, para isso, é vista como não-homem, como objeto. Eis o cerne do paradigma científico moderno que colonizou o mundo e sua separação sujeito-objeto/ homem-natureza. Esse antropocentrismo, no entanto, esconde que não é a espécie humana em sua totalidade que exerce a dominação da natureza autorizada por seu conhecimento racional. Não, é um antropocentrismo onde as mulheres estão excluídas (não-racionais, emotivas) e, talvez, por aqui se mostre a brecha para entender o paradigma (em crise) da dominação da natureza, por não ser um paradigma do cuidado da natureza que, talvez, quem sabe, se coloque a partir das mulheres ou de outros grupos sociais, povos e nacionalidades com suas culturas/epistemes outras. Afinal, foram principalmente os homens que forjaram esse paradigma, como assinalou afirmativamente um de seus próceres, Francis Bacon (1561-1626), e bem destacou criticamente Ramon Grosfogel. Portanto, o patriarcalismo estaria 
subjacente ao antropocentrismo. Mas não só. Esse homem que deveria dominar a natureza era o homem branco e não os povos de cor (como se branco não fosse cor). Aliás, esses povos não-brancos, não-europeus, foram vistos como selvagens, ou seja, da natureza, das selvas e, por serem da natureza deveriam ser dominados, colonizados na melhor hipótese, enfim, deveriam deixar de serem outros! E, ainda mais: uma ciência que naturalizou a matematização da vida informada por uma sociedade que se instituía matematizando tudo com a mercantilização, como bem assinalou Roberto Bartholo, (1986). E assim, uma ciência cada vez mais vista como tecnociência, como destacara Francis Bacon, em que a ciência estaria preocupada com a verdade e a tecnociência estaria preocupada com a eficácia Oliveira, B. (2002). E eficácia, numa sociedade capitalista, é aquela que proporciona a acumulação de capital através da dominação da natureza. E dominação implica uma relação assimétrica em que aquele que domina considera/faz do dominado não aquilo que ele é em sua plenitude, mas aquilo que do dominado interessa ao dominador. Por isso, o dominado é, sempre, mais do que aquilo que é sob relações sociais e de poder assimétricas, em suma, sob relações de dominação/ subalternização. E a natureza passou a ser dissecada em função da dominação visando a acumulação de capital. Para isso, a separação homem-natureza não é/foi só uma questão epistêmica, embora o seja, mas também uma questão ontológica, em que homens/mulheres são expropriados de suas condições metabólicas de produção/reprodução da vida e de suas comunidades/povos/ etnias/nacionalidades. Tornam-se eles/elas, individualizado/as, vendedores/as de sua força de trabalho, portanto mercadorias, no mesmo movimento em que as condições metabólicas necessárias à produção/reprodução da vida passam a ser cercadas (enclosures) como propriedades privadas também mercantilizáveis, tudo isso medido matematicamente, precificados (Altvater, 1995). Tudo isso será potencializado com a revolução (nas relações sociais e de poder) industrial onde o capitalismo se impõe e aprofunda a relação metabólica da sociedade com o uso que se generaliza dos combustíveis fósseis para mover a máquina a vapor (Castro-Gómez, 2005). Pouco se diz que se trata de vapor d'água. Com o desenvolvimento desse "capitalismo fossilista" (Altvater, 1995), o consumo produtivo de matéria e energia dispara, assim como o consumo produtivo da água nas fábricas e nos campos que também, pouco a pouco, vão sendo povoados por máquinas. 
WMA: Do evidente aumento da população e sua concentração nas áreas urbanas, o que se pode deduzir, além de sua própria demanda, sobre o conflito sobre a disponibilidade, acesso e uso da água?

CWPG: Depois que a máquina de guerra estadunidense teve que buscar outro destino para sua enorme capacidade de produção desenvolvida como esforço de guerra (1939-1945) e se impôs a "ideologia do desenvolvimento" que viu subdesenvolvimento por todo lado, o consumo de matéria e energia alcança proporções jamais vistas o que mereceu a caracterização do pósguerra como A Grande Aceleração. O advento da televisão e a ideologia difundida por Hollywood se encarregaram da "fabricação capitalística da subjetividade" (Guatarri e Rolnik, 2000). Do american way of life. Desde então, a urbanização se transformou num fenômeno mundializado deixando de ser um fenômeno de país desenvolvido, para me manter nos termos que passaram a colonizar corações e mentes. Em 1960, dos 3 bilhões de habitantes do planeta 1,8 bilhões eram rurais e 1,2 bilhões eram urbanos. Em 2015, a ONU nos informa que somos aproximadamente 7,2 bilhões, sendo 3,8 bilhões urbanos e 3,4 bilhões rurais. Atentemos para esses números por suas implicações metabólicas planetárias, com suas geografias com intensidades próprias. Observemos que a população urbana disparou de 1,2 bilhões, em 1960, para 3,8 bilhões em 2015, um crescimento de aproximadamente $320 \%$ ! Mas, atenção: a população rural passou de 1,8 bilhões, em 1960, para 3,4 bilhões, em 2015, um crescimento de aproximadamente 190\% ! Nunca tivemos no mundo tantos habitantes nas zonas rurais como hoje, apesar do enorme crescimento da urbanização! Em suma, houve um profundo processo de expropriação de camponeses, povos, etnias e nacionalidades de seus cantões não-urbanos e temos hoje mais habitantes nas zonas rurais.

Consideremos as profundas implicações metabólicas que daí emanam, a começar pela enorme concentração de bilhões de habitantes em cidades que demandam cada vez mais matéria e energia. Evitemos, no entanto, o malthusianismo que tende a se infiltrar quando trazemos essas questões. E sabemos que o malthusianismo exerce, ainda, uma forte influência no campo ambiental com um discurso do medo, do pânico, em nome do que tenta convencer da validade de suas propostas, quase sempre, de controle da população. Também com relação à água, a mesma cantilena é aduzida como se os problemas derivassem do crescimento da população. Entretanto, e aqui mais urna vez, a questão parece ser mais complexa do que esse reducionismo, até porque se a população mundial cresceu 2,4 vezes desde 
os anos 1960 enquanto a demanda por água cresceu 6 vezes, segundo nos informa o diretor da Agencia Nacional de Águas do Brasil, Jerson Kelman. No Canadá, entre 1972 e 1991, enquanto a população cresceu $3 \%$ o consumo de água cresceu $80 \%$, segundo a ONU (GEO-3). Considerandose o nível de vida da população canadense, os dados acima quando comparados com o crescimento da população mundial e a demanda global por água vemos que é o crescimento exponencial de populações com o nível de vida europeu e norte-americano que está aumentando a pressão sobre esse e outros recursos naturais de modo insustentável. Assim, a demanda por água cresce mais que o crescimento demográfico, indicando que devemos buscar em outro campo as razões do desequilíbrio hidrológico. A urbanização se coloca como um componente importante dessa maior demanda por água. Um habitante urbano consome em média 3 vezes mais água do que um habitante rural, assim como a pegada ecológica (footprint), água incluída, entre os habitantes do Primeiro Mundo e os do Terceiro Mundo é extremamente desigual. Segundo Ricardo Petrella, "um cidadão alemão consome em média nove vezes mais água do que um cidadão na Índia" (entrevista a Agencia Carta Maior, durante o $10^{\circ}$ Fórum Alternativo da Água em Florença - 2003). Além disso, as cada vez

Os blocos capitalista e comunista em que estava dividido o mundo até pouco tempo tinham muitos pontos de controvérsia ideológica, mas ambos coincidiam em sua admiração pelo desenvolvimento técnico e competiam para mostrar avanços nesse terreno. Sob esta mentalidade, se empreenderam projetos em grande escala, com armazenamentos de água atrás de represas de concreto, com dispositivos para geração de energia, controle de inundações e derivados para a irrigação agrícola. Podemos assinalar alguns exemplos destas obras monumentais. Nos Estados Unidos, a represa Hoover no rio Colorado, ou a cadeia de represas construída na bacia do rio Tennessee. Na União Soviética, o projeto Dnipropertovsk, na Ucrânia, representou um vigoroso impulso para a industrialização socialista. Mais tarde, ambas potências difundiram seus modelos sociopolíticos e de desenvolvimento tecnológico em suas respetivas áreas de influência. No rio Nilo, a União Soviética fez replicar sua capacidade tecnológica na construção da represa de Assuan (no Egito). No México, com apoio financeiro internacional, a Comissão Federal de Eletricidade construiu a represa Chicoasén, uma das 10 maiores represas do mundo.

Melville, R. e Cirelli, C. (2000)

La crisis del agua.

Sus dimensiones ecológica, cultural y política

Revista Memoria, (134) 
maiores aglomerações urbanas exigem captação de água a distancias cada vez maiores, para não nos referirmos à energia que por todo lado implica mudar o uso e o destino (e os destinatários, não nos esqueçamos) da água, não só quando é produzida como hidrelétrica, mas também nas termelétricas e nas usinas nucleares, onde a água é amplamente utilizada para fins de resfriamento das turbinas. Segundo a ONU, somente nos últimos 50 anos, entre 40 e 80 milhões de habitantes, quase sempre camponeses e populações originárias, foram atingidos por inundação de suas terras para fins de construção de diques e barragens (GEO-3:151). Dos 227 maiores rios do mundo, 60\% foram barrados por algum dique nesse mesmo período e, ainda em 1998, estavam sendo construídos nada menos que 349 diques com mais de 60 metros de altura em diferentes países do mundo, em grande parte financiados pelo Banco Mundial. Roberto Melville e Claudia Cirelli (2000) nos dão uma boa caracterização de todo esse processo (veja a caixa).

O crescimento da população urbana e da industrialização, com a consequente expansão da economia mercantil que the acompanha e impulsiona, estão impondo mudanças significativas no modo de organização do espaço em todo o mundo. As monoculturas passam a predominar nas paisagens rurais visando abastecer os centros urbanos tanto no interior dos diferentes países, como para garantir o fluxo de matéria entre os países, fluxo esse sobretudo dirigido aos países hegemônicos, sem o que os valores de uso concretos não podem ser produzidos e o usufruto da riqueza tangível, implicado num estilo de vida consumista tão ciosamente induzido pelos meios de comunicação de massas, possa ser praticado. Não sem razão, a irrigação e a captação de águas subterrâneas se generaliza, tanto para fins agrícolas como de abastecimento urbano-industrial, com o uso crescente em todo o mundo, sobretudo nos últimos 30 anos, de bombas a diesel e de poços artesianos. O problema da água, literalmente, se aprofunda. Assim, numa outra escala geográfica, agora global, a lógica industrial volta a se encontrar com a água, relação essa que esteve presente já no início da revolução industrial com a máquina a vapor (d’água). Ali, o carvão viera substituir a madeira no aquecimento da água, haja vista a escassez de madeira para esse fim. O espaço urbano é o locus por excelência da economia de mercado. Afinal, o ambiente urbano torna praticamente impossível a chamada economia natural, isto é, aquela que não requer a mediação mercantil. Assim, a economia gerada pela expansão da população urbanizada introduz a mediação do ilimitado nas relações sociedade-natureza por meio do dinheiro. A tensão entre o simbólico (o dinheiro), e a materialidade do mundo se instaura enquanto questão ambiental. Pouco a pouco os motores 
foram se transformando e se tomando mais eficientes em termos energéticos sem, entretanto, deixar de consumir água. Afinal, maior eficiência energética implica maior capacidade de transformação da matéria e, com isso, maior consumo de água, maior dissipação de energia sob a forma de calor $\left(2^{\circ}\right.$ princípio da termodinâmica) e, nas turbinas concretamente, maior necessidade de água para resfriamentos. Assim, a maior eficiência que se obtém numa escala micro ao se generalizar torna possível a maior transformação global da matéria e, assim, acelera a transformação global da natureza do que o efeito estufa e as mudanças climáticas globais são uma demonstração. Enfim, é de uma desordem ecológica global que vimos assinalando. Assim, as soluções encontradas à escala micro para resfriar as turbinas, ou o termostato que desliga automaticamente a máquina quando atinge certo grau de aquecimento, não são transplantáveis para a escala do planeta como um todo e que pudesse amenizar o aquecimento global provocado pelo efeito estufa. Como se vê, a água flui por meio da agricultura, da indústria, do nosso estilo de vida e a pressão sobre seu uso está longe de ser explicada pelo crescimento da população, simplesmente, como quer a matriz malthusiana de pensamento.

WMA: Isso significa que a crescente eficiência da indústria aumentou contraditoriamente as desigualdades em termos de acesso à água?

CWPG: Hoje, com o motor a diesel se busca água no subsolo e, com isso, introduzem-se no nosso léxico cotidiano expressões como aquíferos, já que as águas superficiais e mesmo os lençóis freáticos já não se mostram suficientes, pelo menos na hora e nos lugares desejados. Cada vez é maior o saque aos aquíferos e, deste modo, introduz-se um componente novo na injustiça ambiental generalizada no mundo e em cada país com a expansão da racionalidade económico-mercantil engendrada pelo capitalismo. Afinal, a captação de água à superfície era, de certa forma, mais democrática na medida em que a água estava ao alcance de todos, literal e materialmente. Com a captação de águas nos subterrâneas os meios de produção, as bombas a diesel, se tornam sine qua non conditio e como nem todos dispõem desses meios, a injustiça ambiental ganha novo contorno por meio do desigual acesso à água. Nos anos 90, na América do Norte 50\% de todo o consumo dos habitantes foi obtido em águas subterrâneas, segundo a ONU (GEO-3). Na China também é cada vez maior a proporção de águas captadas subterraneamente. Se, de um lado, com a irrigação podemos aumentar a área de terras para a agricultura é preciso considerar os vários lados dessa prática. Cerca de $20 \%$ dos solos irrigados no mundo estão hoje salinizados e, assim, impraticáveis para a 
agricultura (GEO-3)! Em Madras na Índia, a captação de águas subterrâneas levou a um rebaixamento de tal ordem do lençol freático que a águas salgadas avançaram pelo subsolo cerca de 10 quilômetros continente adentro trazendo sérios problemas de abastecimento (ONU-GEO-3). Consideremos, ainda, que essa expansão generalizada da economia mercantil vem avançando sobre áreas como manguezais e outros humedales, áreas riquíssimas do ponto de vista das cadeias alimentares da vida, assim como sobre áreas florestais que, como a Amazónia, ou como as áreas de páramos, abrigam enorme quantidade de água nelas mesmas.

Essas áreas, em particular as florestas tropicais, cumprem um papel importantíssimo para o equilíbrio climático global pela umidade que detém e, assim, contribuem para que as amplitudes térmicas, as diferenças entre as temperaturas máximas e as mínimas diárias e anuais, não aumentem ainda mais como vem ocorrendo, em grande parte pelo próprio desmatamento. Relembremos que com a aplicação aos próprios meios de transportes do princípio da máquina a vapor, o deslocamento da matéria se tornou possível numa proporção que não mais depende dos ventos e das calmarias, das marés e correntes marinhas, e tampouco dos braços escravos que moviam as embarcações com seus remos. Com isso, a injustiça ambiental se generaliza ainda mais, na medida em que as matérias ao se deslocarem no sentido geográfico que as relações sociais e de poder determinam, escrevem uma geografia desigual dos proveitos e dos rejeitos. Afinal, a água circula não só pelos rios, pelo ar, com as massas de ar, ou pelos mares e correntes marinhas, mas também sob a forma social de mercadorias várias -tecidos, automóveis, matérias-primas agrícolas e minerais- enfim, sob a forma de mercadorias tangíveis e, só assim, podemos entender o desequilíbrio hidrológico impulsionado pela lógica de mercado generalizada pelo capitalismo. Afinal, para se produzir um quilo de qualquer grão, seja de milho ou de soja, se demanda, com as atuais técnicas agrícolas, 1.000 litros de água! Um quilo de frango consome 2.000 litros de água! Fixemos a imagem de um caminhão frigorífico em plena Rodovia Transamazônica (Altamira - PA) transportando frango produzido em Chapecó, Santa Catarina, a cerca de 3.500 quilômetros, para termos urna ideia do custo energético e hídrico desse frango para a sociedade brasileira e o planeta como um todo. E isso para não falar do que significa para as populações locais dos lugares de Altamira - PA, que importam esse frango que, por essa lógica, parece que não conseguem sequer criar galinha. A racionalidade económico mercantil não poderia ganhar um exemplo mais radical de ineficiência ambiental global. Não olvidemos que 
quando exportamos frango para a Europa e Oriente Médio, e o fazemos até mesmo de avião, estamos exportando energia e água. Não é demais repetir: 1 quilo de frango consome 2.000 litros de água! O mesmo raciocínio pode ser feito com o alumínio, o papel, a celulose.

\section{WMA: Então, a ineficiência ambiental global vai muito além da desigualdade} em termos de captação de água?

CWPG: Quando essas regiões exportadoras estiverem implicadas em algum stress hídrico, como soem estar cada vez mais, como recentemente esteve Santa Catarina no Sul do Brasil, devemos ter em conta as limitações de qualquer especialista para dar conta dessa problemática que, embora se manifeste em cada local de modo específico está, na verdade, submetida a um processo global de desenvolvimento desigual, mas combinado, como estamos vendo. As indústrias e plantações altamente consumidoras de água, ou que nela lançam muitos rejeitos, como são os casos das indústrias de papel e celulose ou de bauxita-alumínio (no caso do alumínio, para cada 1 tonelada de bauxita deixa-se no ambiente 15 toneladas de urna lama vermelha altamente poluidora), vêm se transferindo, desde os anos 70, para os países ricos em matérias brutas -energia, minerais, solos, sol, água- de onde exportam o proveito e deixam os rejeitos. A ideologia do desenvolvimento abênçoa essa lógica, para o que muito vem contribuindo os organismos multilaterais (FMI, Banco Mundial e a OMC) com suas políticas de ajuste, fomento, ajuda e apoio. Um exemplo concreto pode-nos ajudar a fixar a tese central: a separação do minério de cobre numa jazida implica abandonar cerca de 99,5\% da matéria revolvida como rejeito! A revolução nas relações sociais e de poder implicada na nanotecnologia, com sua desmaterialização e transmaterialização, implica mais água por todo lado para tratar a matéria nesse nível nanoscópico. A água é por todo lado amplamente usada e, diferentemente de qualquer commodity, é insubstituível. Pode-se melhorar a eficiência de seu uso, mas não se pode prescindir dela. Daí todo o significado de se considerar a vida como um outro estado da água e de tomar a sociedade com todas as suas contradições como parte do ciclo da água. Depois da Natureza Passos para uma Ecologia Política Antiessencialista - Arturo Escobar ${ }^{8}$ Afinal, a atual disputa pelo controle e gestão da água, parte da crise ambiental, revela, também, a crise da racionalidade instrumental hegemônica na ciência da sociedade modernocolonial.

8 http://www.niesbf.uerj.br/arquivos/Ecologia2OPolitica_Escobar.pdf 
WMA: O ciclo da água deve ser entendido de uma maneira extremamente ampla, dinâmica e complexa, como um todo, uma unidade, ou seja, tudo o que conhecemos e nos rodeia, desde a diversidade, inclusive a nós mesmos, além do cotidiano, faz parte do ciclo da água?

CWPG: No caso da água, a própria natureza líquida da matéria parece escapar aqueles que tentam aprisioná-la às especialidades com que nossa departamentalizada universidade forma, conforma e deforma seus profissionais. A água, afinal, não cabe naquela simplificação típica dos livros didáticos, e que comanda o imaginário dos cientistas, em que uma superfície líquida -o mar, um lago, um rio- submetida a radiação solar transforma-se em vapor e, depois, em nuvens que se condensam e precipitam, dando origem a rios e lagos, e outras superfícies líquidas, que submetidas a radiação solar..., enfim, o ciclo da água. Ciclo abstrato, até porque ignora que aquele que desenha o ciclo da água, assim como aquele que está aprendendo o que não é o ciclo da água, são seres humanos que, eles mesmos, enquanto seres vivos que são, contém em seus corpos, em média, mais de $70 \%$ de água. Quando transpiramos ou urinamos estamos imersos no ciclo da água. O ciclo da água não é externo a cada um de nós, passa por nossas veias materialmente e não só literalmente. Nosso sangue é, em $83 \%$, água. E não só: quando nos sentamos à mesa para comer deveríamos saber que o cereal, a fruta e o legume não só contém em si mesmos, água, como também todo o processo de sua produção agrícola envolveu um elevado consumo de água. A agricultura é responsável pelo consumo de $70 \%$ da água de superfície no planeta! Assim, é todo o sistema agrárioagrícola que está implicado no "ciclo da água"! O mesmo pode ser dito dos pratos de cerâmica ou de metal, dos talheres de alumínio ou de aço inoxidável que para serem produzidos exigem um elevadíssimo consumo de água, além de lançarem resíduos líquidos em altíssima proporção no ambiente como rejeito. Em todo o mundo, a indústria é responsável pelo consumo de $20 \%$ da água superficial. Todo o sistema industrial se inscreve, assim, como parte do "ciclo da água" e, deste modo, vai se mostrando toda a complexidade da relação sociedade-natureza implicada no ciclo da água, muito longe dos especialistas formados no simplificador paradigma atomístico-individualista-reducionista que, embora seja visto como parte da solução é, também, parte do problema (Porto-Gonçalves, 1989). Deste modo, o sistema agrário-agrícola e todo o sistema industrial se inscrevem como parte do ciclo da água e se desequilíbrio há com relação à água ele deve ser buscado nas complexas relações sociedade-natureza que manifestam também no sistema hídrico suas próprias contradições societárias. 
A água, como se infiltra em tudo -no ar, na terra, na agricultura, na indústria, na nossa casa, em nosso corpo- revela nossas contradições socioambientais talvez melhor que qualquer outro tema. Afinal, por todo lado onde há vida há água. Atentemos, pois, que a vida deve ser entendida para além de sua dimensão estritamente biológica, posto que a água está presente na sociedade por todo lado - na agricultura, no artesanato e na indústria. Nosso modo de comer, mesmo nas cidades, está em grande parte condicionado pelo modo como nossos alimentos são produzidos nos campos; nosso próprio abastecimento de energia depende de barrar rios e mudar o destino e os destinatários da água (inclusive, para fins de energia). A questão da água vê-se, urbaniza o debate sobre o sistema agrário-agrícola e por meio da questão ambiental põe em xeque todo o estilo de vida alimentado por um modo de produção que o estimula para acumular riqueza virtual -dinheiro- e, com isso, pondo em risco a riqueza da água, da terra, do solo, da vida, na sua concretude.

\section{O Discurso da Escassez}

WMA: O discurso da escassez de água tem sido amplamente aceito e apropriado pela mídia, bem como por vários círculos importantes de cientistas influentes que a respaldam, o que teve um impacto significativo na geração de políticas públicas e na tomada de decisões, finalmente influenciando/limitando o comportamento da população civil, não apenas nos países do Sul Global, mas em escala planetária. Nesse contexto, em quais argumentos você encontra oportunidades para refutá-lo e propõe outra visão, principalmente em relação à gestão da água?

CWPG: Argumentos pouco consistentes vêm sendo brandidos no afã de legitimar um modo específico de gestão das águas, como se fosse o único modo de gestão possível. É o caso do discurso da escassez que nos diz que, embora o planeta tenha três de suas quatro partes de água, 97\% dessa área é coberta pelos oceanos e mares e, por ser salgada, não estaria disponível para consumo humano; que, dos 3\% restantes, cerca de $2 / 3$ estão em estado sólido nas geleiras e calotas polares e, assim, também indisponíveis para consumo humano; deste modo, menos de $1 \%$ da água total do planeta seria potável, num discurso de escassez de tal forma elaborado que, ao final, o leitor já está com sede. Essa estatística, ao tentar dar precisão científica ao discurso da escassez, comete erros primários do próprio ponto de vista científico de onde procura retirar sua legitimidade. A começar por boa parte de glaciares que se derretem em determinadas épocas do ano e alimentam a sociedade do 
entorno, como se vê no Chile, na Colômbia, na Bolívia. Além disso, e mais importante por sua dimensão, a água doce que circula e que está disponível para consumo humano e toda sorte de vida não-humana que o planeta conhece é, em grande parte, fruto da evaporação dos mares e oceanos: são cerca de $505.000 \mathrm{Km}^{3} / \mathrm{ano}$, ou seja, uma camada de 1,4 metro de espessura evapora anualmente dos oceanos e mares que, embora sejam salgados, não transmite o sal na evaporação. Fôssemos fazer o mesmo raciocínio para a radiação solar que efetivamente se transforma em biomassa pela fotossíntese, fundamental para a produção dos nossos alimentos, por exemplo, e ficaríamos ainda mais surpresos, posto que não é mais do que $0,06 \%$. A maior parte da radiação solar lançada sobre a terra ou é refratada (albedo), move ventos e tempestades, produz evaporação e evapotranspiração, enfim, não está disponível para consumo humano, muito embora não trabalhasse a natureza dessa forma e a própria vida na Terra seria impossível pelo excesso de radiação solar que chega. Todavia, ainda não vemos o discurso da escassez da radiação solar. Enfim, a água disponível para a vida é, pelo menos desde o recuo da última glaciação, entre 12.000 e 18.000 anos atrás, a mesma desde então até os nossos dias, com pequenas variações. Se maior não é a quantidade de água potável é porque, na verdade, maior não pode ser, a não ser pela regressão das calotas polares e dos glaciares fruto de mudanças climáticas planetárias geradas por causas complexas e, muito recentemente em termos da história do planeta, pela matriz energética fossilista pós-revolução (nas relações sociais e de poder por meio da tecnologia) industrial.

O discurso da escassez está longe de ser neutro ou ingênuo sendo, sim, um discurso interessado. É que a tradição da ciência econômica não tem nada a dizer sobre a riqueza, na medida em que seu conceito chave é o de escassez que, rigorosamente, é o contrário de riqueza. Afinal, riqueza é o que é abundante e não o que é escasso. Nos marcos do pensamento econômico hoje hegemônico, a água vem sendo pensada como um bem econômico mercantil a partir do conceito de escassez. Na medida em que algo é pensado (e instituído) como escasso, acredita-se, pode ser objeto de compra e venda, pode ser objeto de mercantilização, posto que ninguém compraria algo que é comum a todos por sua abundância, enfim como algo que está disponível enquanto riqueza para todos. Assim, o discurso da escassez, prepara a privatização da água. Mais do que isso, a produz, pois como a própria palavra indica, privatizar é privar quem não é proprietário privado do acesso a um bem. Enfim, a privatização produz a escassez (Barlow e Clarke, 2003).

9 Barlow, M. e Clarke, T. (2003), em seu livro Ouro Azul, mostraram que: "Os países reduzem as 


\section{Para além da Colonialidade}

WMA: O que os conhecimentos e práticas ancestrais podem contribuir em relação ao uso e manejo da agua, mesmo que sejam encontrados ameaçados e silenciados, mas refletidos e atualizados continuamente e com dificuldade, no cotidiano de diferentes povos e culturas antigas? Finalmente, como podemos abordar e apropriar-se desse outro estado da água como "estado vivo", para sermos autogestões conscientes e fugirmos da injustiça ambiental que, de alguma forma, todos exercemos?

CWPG: É preciso sublinhar que embora estejamos diante de urna desordem ecológica global, particularmente visível quando abordado a partir da água, seus efeitos estão longe de serem distribuídos igualmente pelos diferentes segmentos e classes sociais, pelas diferentes regiões e países do mundo, assim como estão muito desigualmente distribuídos os meios para lidar com a questão. Não bastassem esses efeitos, há um outro, pouco debatido mas de efeitos igualmente graves, que diz respeito ao fato de que outras diferentes formas de lidar com a água desenvolvidas por diferentes povos e culturas em situações muito próprias, estão impossibilitadas de serem exercidas até porque essa desordem ecológica de caráter global produz desequilíbrios locais de novo tipo, cujas dinâmicas hídricas estão longe de constituir um padrão que possa servir de referência para as práticas culturais. Esse problema vem sendo acusado por populações camponesas em diferentes regiões e lugares no Brasil, que não mais conseguem fazer as previsões de tempo com a mesma precisão que faziam há não mais do que 30 anos (anos 1970). Assim, diferentes culturas e, com elas, diferentes modos de se relacionar com a natureza também vão sendo extintos e, com eles, todo um enorme acervo de conhecimentos diversos sobre a forma de lidar com as dinâmicas naturais.

É sempre bom lembrar que a água é fluxo, movimento, circulação. Portanto, por ela e com ela flui a vida e, assim, o ser vivo não se relaciona com a água: ele é água. É como se a vida fosse um outro estado da matéria água, além do líquido, do sólido e do gasoso - estado vivo. Os cerca de 8 milhões de

taxas locais e as normas de proteção ambiental para permanecer competitivos. (...) Os governos ficam, então, com uma capacidade fiscal reduzida para recuperar as águas poluídas e construir infraestruturas para proteger a água; ao mesmo tempo, torna-se mais difícil regulamentarem a prevenção de poluições posteriores". Em suma, "vender água no mercado aberto não atende as necessidades de pessoas sedentas e pobres (...) pelo contrário, a água privatizada é entregue àqueles que podem pagar por ela, tais como cidades e indivíduos ricos e indústrias que usam água intensivamente, como as de tecnologia de ponta e agricultura" (Nota de CWPG). 
quilómetros quadrados relativamente contínuos de floresta ombrófila, em grande parte fechada, no Brasil, Bolívia, Colômbia, Equador, Guianas, Peru, Suriname e Venezuela com suas 350 toneladas de biomassa por hectare em média é, em 70\%, água e, assim, se constitui num verdadeiro "oceano verde" de cuja evapotranspiração depende o clima, a vida e os povos de extensas áreas da América Central e do Sul, do Caribe e da América do Norte, enfim, do mundo inteiro. Assim, a água não pode ser tratada de modo isolado, como a racionalidade instrumental predominante em nossa comunidade científica vem tratando, como se fosse um problema de especialistas. A água tem que ser pensada como território, isto é, como inscrição da sociedade na natureza com todas as suas contradições implicadas no processo de apropriação da natureza pelos homens e mulheres por meio das relações sociais e de poder. $\mathrm{O}$ ciclo da água não é externo à sociedade. Assim, a crise ambiental, vista a partir da água, também revela o caráter de crise da sociedade, assim como de suas formas de conhecimento.

Por isto mesmo, a análise da água requer o tempo todo, que se a considere na sua geograficidade, isto é, na inscrição concreta da sociedade na sua geografia, com as suas diferentes escalas local, regional, nacional e mundial imbricadas num processo complexo de articulação ecológico e político. Só assim se explica a transferência dos países ricos em capital para os países ricos em água de várias atividades altamente consumidoras, como as indústrias de papel e celulose e de alumínio. A desordem ecológica global está, na verdade, associada ao processo que des-locou completamente a relação entre lugar de extração, de transformação e produção da matéria e o lugar de consumo com a revolução (nas relações sociais e de poder por meio da tecnologia) industrial. Com a maior eficácia energética foi possível explorar minerais em proporções ínfimas em sua concentração nas diferentes jazidas existentes na geografia do planeta, assim como na sua natureza nanométrica. Os rejeitos ou foram deixados nos locais onde as pessoas valem menos - nunca é demais lembrar o racismo subjacente ao sistema-mudo moderno-colonial- e os produtos foram e são levados limpos para os lugares e para pessoas que podem gozar os proveitos, qualidade de vida essa que quase sempre os que dela desfrutam não incluem os custos dos rejeitos, enfim, ignora a injustiça ambiental em que se ancora seu modo de vida. Dada a importância do tema da água é fundamental que ouçamos a observação de Boaventura de Sousa Santos que, rompendo com a colonialidade do saber e do poder, nos convida a que não desperdicemos as múltiplas experiências que a humanidade nos legou e que o primeiro-mundismo que nos coloniza não nos deixa enxergar. 
Diferentes instituições foram criadas por diferentes povos ao longo da história (e suas geografias) estabelecendo regras as mais variadas de uso da água. Os povos árabes e arabizados detêm a esse respeito uma grande tradição de convivência com a água em áreas desérticas e semiáridas. Os espanhóis são herdeiros de muitas dessas regras para lidar com la sequía e suas lições podem ser aprendidas em Yerma, obra teatral de Garcia Lorca. Os sertanejos do nordeste brasileiro desenvolveram toda urna sabedoria que vai da previsão do tempo, que mereceu, inclusive, a atenção da NASA pelo seu elevado índice de precisão, ao aproveitamento máximo do mínimo de água com que têm que se haver diante da irregularidade das precipitações, com suas culturas de vazante, conforme destaca o geógrafo Aziz Ab Saber, e também com as cisternas de captação de água conforme o grande movimento da - Articulação do Semiárido (ASA). Os chineses, hindus, os maias e os astecas, que chegaram a ser chamados pelos historiadores de civilizações do regadio, têm tradições que merecem ser estudadas, agora que a água parece convocar a todos a buscar novas formas de gestão e controle.

Portanto, caso não se queira desperdiçar, mais urna vez, por preconceito, a diversidade de experiências que a humanidade desenvolveu como é característico do etnocentrismo ocidental, não nos faltará inspiração para buscarmos soluções, sublinhe-se, no plural. Tudo indica que o planeta como um todo começa a dizer, tanto ecológica como politicamente, que o local já não é isolável, tal como o foi durante o período áureo do colonialismo e do imperialismo clássicos. E não nos iludamos com os debates que se colocam meramente no campo epistêmico, buscando outros paradigmas, embora devamos ficar atentos a esse campo. É que os paradigmas são instituídos através de processos social e historicamente instituintes por grupos sociais que os instituíram (Cornelius Castoriadis, 1982). Enfim, como não há instituições que não sejam e não tenham sido instituídas, é bom prestarmos atenção aos sujeitos instituintes que estão pondo esse-mundo-que-aí-está em xeque e que apontam, com suas lutas, que outro mundo não só é possível, como necessário. 


\section{Referências}

Altvater, E. (1995). O Preço da Riqueza: Pilhagem Ambiental e a Nova (Des) ordem Mundial. Unesp.

Barlow, M. e Clarke, T. (2003). Ouro Azul - Como as grandes corporações estão se apoderando da água doce do nosso planeta. M. Brooks.

Bartholo, R. (1986). Razão e Moeda. A ciência moderna como forma de conhecimento e a forma dinheiro da mercadoria como síntese social. Novos Rumos, 1, p. 211-226. https://www.escavador.com/sobre/2319623/roberto-dos-santos-bartholo-junior

Castoriadis, C. (1982). A Instituição Imaginária da Sociedade. Paz e Terra.

Castro-Gómez, S. (2005). La hybris del punto cero: ciencia, raza e ilustración en la Nueva Granada (1750-1816). Editorial Pontifícia Universidad Javeriana. http://www.scielo. org.co/scielo.php?script=sci_arttext\&pid=S0120-48072006000200018

Guatarri, F. e Rolnik, S. (2000). Micropolítica: cartografias do desejo. Vozes.

Melville, R. e Cirelli, C. (2000). La crisis del agua. Sus dimensiones ecológica, cultural y política. Revista Memoria,(134). https://www.researchgate.net/ publication/279446217_La_crisis_del_agua_Sus_dimensiones_ecologica_cultural_y_ politica

Oliveira, B. (2002). Francis Bacon e a fundamentação da ciência como tecnologia. UFMG.

Porto-Gonçalves, C-W. (1989). Os (Des)caminhos do Meio Ambiente. Contexto.

(2004) O desafio ambiental. Rio de Janeiro: http://www.planetaverde.org/arquivos/ biblioteca/arquivo_20180702143948_7222.pdf

(2005) Água não se Nega a Ninguém (A necessidade de ouvir outras vozes). Revista Polis. (5); pp. 39-69.

(2007). A luta pela apropriação e reapropriação social da água na América Latina. In Fernandes, B.M. Campesinato e Agronegócio na América Latina: A questão agrária atual. Expressão popular.p 195-221.

(2011). A geopolítica da água e a crise do conhecimento. In Trevisol, Joviles Vitório e Scheibe, Luiz Fernando (Org). Bacia Hidrográfica do Rio do Peixe: natureza e sociedade. Unoesc.

(2000). As Minas e os Gerais - Breve ensaio sobre desenvolvimento e sustentabilidade a partir da Geografia do Norte de Minas. In Guimarães, P. W. et al. Cerrado e desenvolvimento: tradição e atualidade. Unimontes, pp. 19-45. 